\title{
Investigation of relationship between spiritual intelligence and quality of life in nurses of Birjand teaching hospitals
}

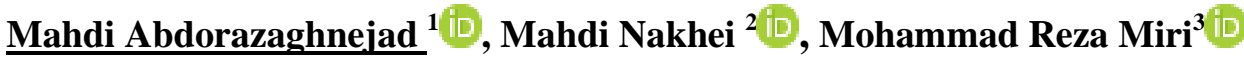

\begin{abstract}
Spiritual intelligence is a set of abilities to take advantage of religious resources that can predict a person's quality of life and adjustment. The aim of this study was to investigate the relationship between spiritual intelligence and quality of life in nurses of Birjand teaching hospitals in a descriptive-analytical and crosssectional study. Data were collected by using the Spiritual Intelligence Questionnaires (SISRI-24) and Quality of Life (SF36) and analyzed using the correlation and t-tests. In this study, 187 subjects were included in the study, of which $42.2 \%$ were male and $58.8 \%$ were female. The average score of spiritual intelligence of the subjects was 48 , which is lower than average. Based on the results of correlation coefficient test, there was a significant relationship between spiritual intelligence and emotional health $(\mathrm{r}=0.77)$ and the individual's general health score $(\mathrm{r}=0.20)$.

Based on the results, the spiritual intelligence score of the subjects was moderate and low. On the other hand, spiritual intelligence predicted some areas of quality of life in nurses, Therefore, the implementation of programs aimed at increasing the spiritual intelligence of individuals can increase the quality of life of nurses.
\end{abstract}

Key Words: Nurses, Quality of Life, Spiritual Intelligence

Citation: Abdorazaghnejad M. Nakhei M. Miri MR. [Investigating the relationship between spiritual intelligence and quality of life in nurses of Birjand teaching hospitals]. J Birjand Univ Med Sci. 2020; 27(3): 301-307. [Persian].

DOI http://doi.org/10.32592/JBirjandUnivMedSci.2020.27.3.108

\footnotetext{
${ }^{1}$ Department of Islamic Studies, School of Medicine, Birjand University of Medical Sciences, Birjand, Iran

${ }^{2}$ Department of Islamic Studies, Birjand University of Medical Sciences, Birjand, Iran

3 Social Determinants of Health Research Center, Birjand University of Medical sciences, Birjand, Iran
}

Corresponding author; Department of Islamic Studies, School of Medicine, Birjand University of Medical Sciences, Birjand, Iran. Tel: +985632395670 Fax: +985632430083 


\section{بررسى رابطه هوش معنوى و كيفيت زندىى در يرستاران بيمار ستانهاى آموزشى بيرجند}

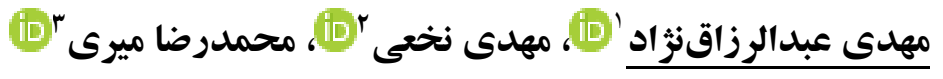

\section{جـكيده}

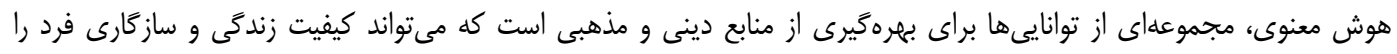

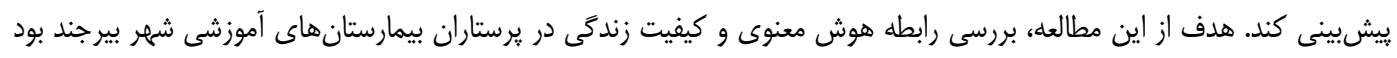

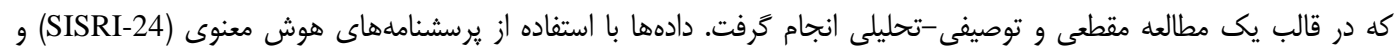

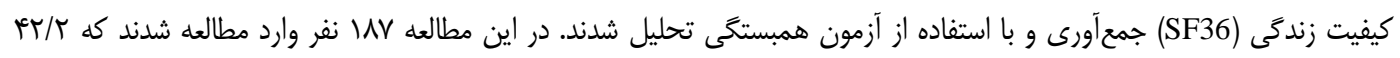

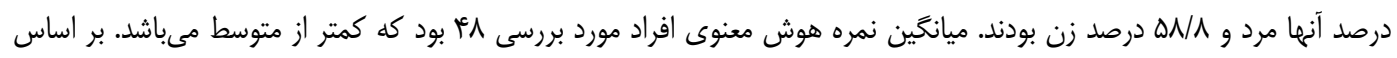

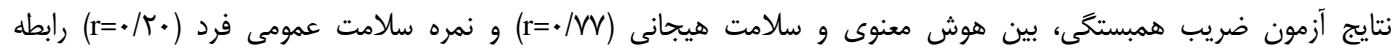

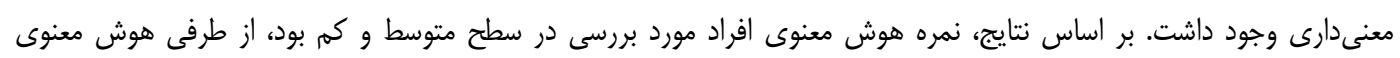

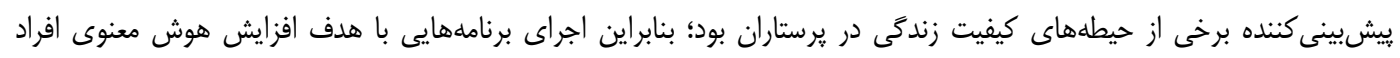

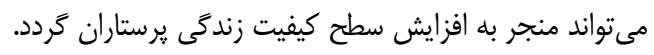
وازههاى كليدى: كيفيت زندگى، يرستاران، هوش معنوى

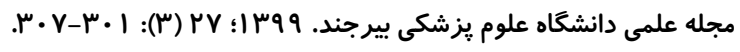

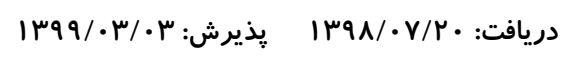

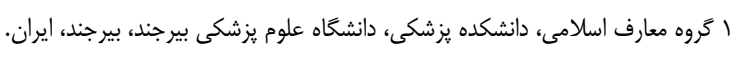

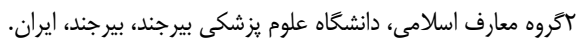

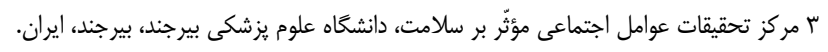

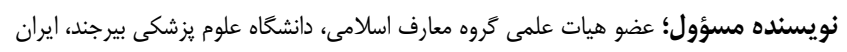

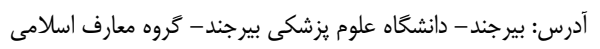




\section{روش تحقيق}

مقل مله

اين مطالعه بلهورت مقطعى و توصيفى -تحليلى بر روى

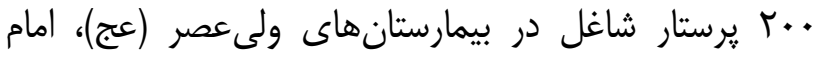

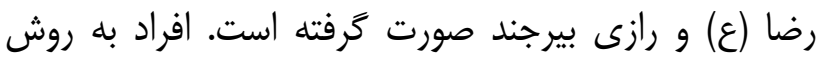

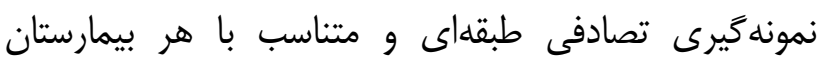

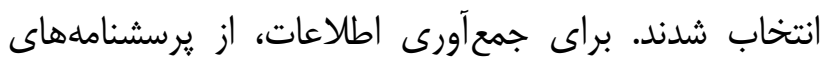

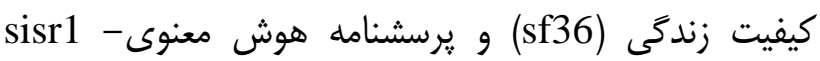

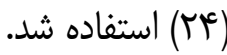
يرسشنامه كيفيت زندگى (sf36)' داراى عس سؤال در دو حيطه جسمى و روانى است كه هشت قلمرو مرتبط با سلامت

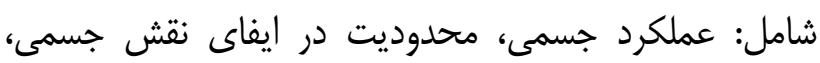

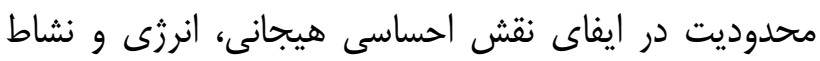

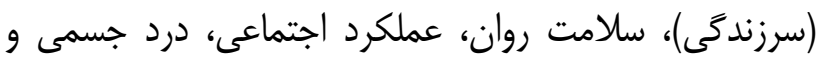

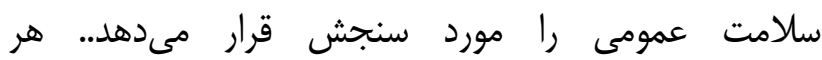

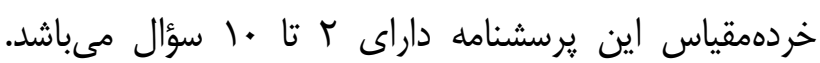

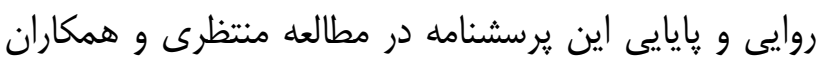
تأييد شده است. در اين ابزار با افزايش نمره، سطح بهر بهرت

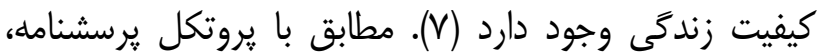

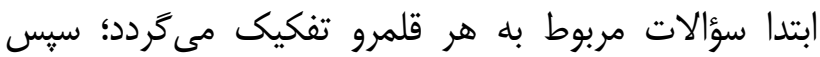
براى محاسبه نمره كل يرسشنامه، ميانخين اعداد به دست

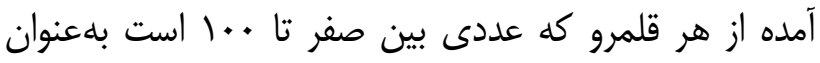

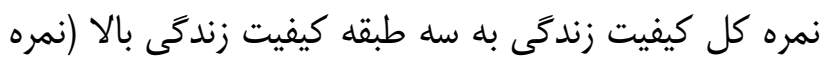

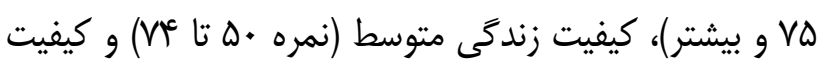

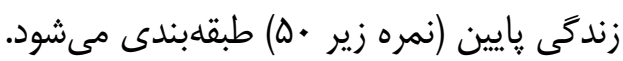

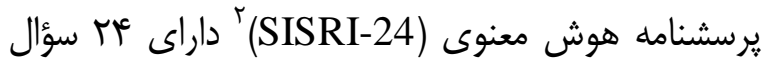
و شامل جهار مؤلفه: تفكر انتقادى وجودى (V) سؤال)،

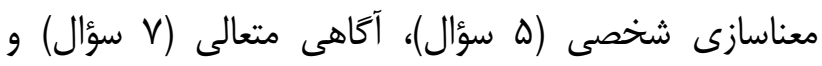

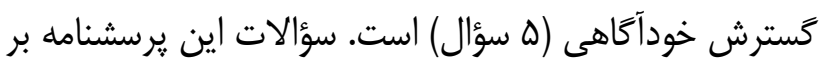

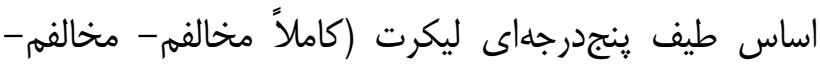

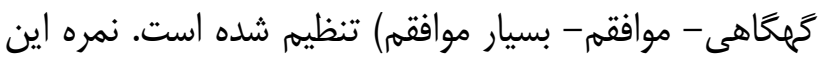
مقياس مىتواند بين صفر تا عه در نوسان باشد؛ نمره بالا

\footnotetext{
${ }^{1}$ The Short Form Health Survey (SF-36)

${ }^{2}$ The Spiritual Intelligence Self Report Inventory SISRI-24
}

هوش معنوى در سالهاى اخير مورد توجه يزوهشگران قرار گرفته است. هوش معنوى مجموعهاى از توانايىها براى دهاى بهره

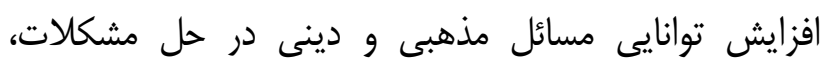

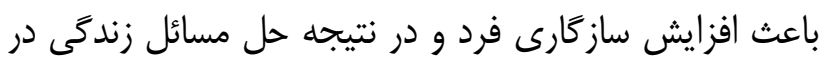

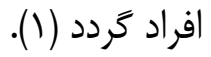

كيفيت زندگى از جنبههاى مهرم زندگى است. كيفيت

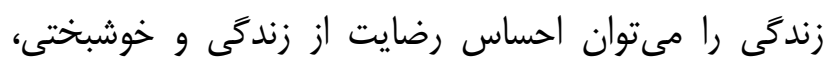

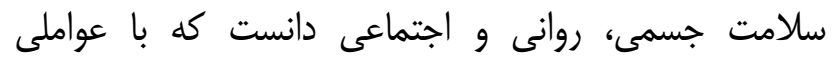

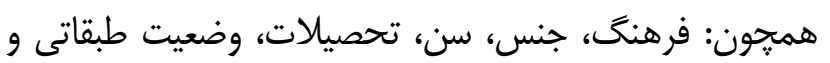
محيط اجتماعى در ارتباط است (r).

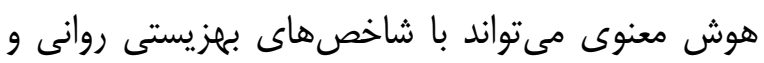

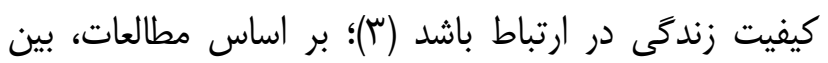
هوش معنوى و برخى حيطههاى كيفت زندگى رابطه وجود دارد (ז). (l).

يرستاران بزركترين گروه ارائهدهنده خدمات سلامت در

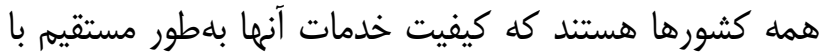
اثربخشى سيستمهاى بهداشتى درمانى در ارتباط است (ه).

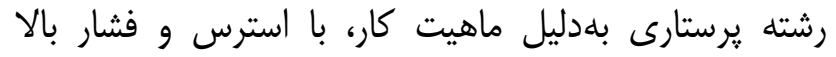

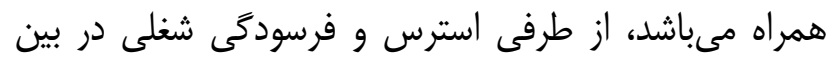

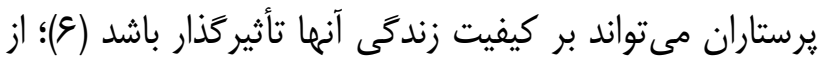
اين رو بررسى و توجه به كيفيت زندكى در يرستاران و رابطه

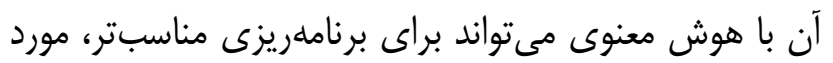

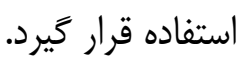
از آنجايى كه ارتقاى كيفيت زندگَى يرسنل از عودامل مهرم يايدارى و اثربخشى سيستم بهداشتى و درمانى استو بلددليل

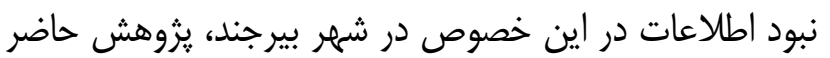

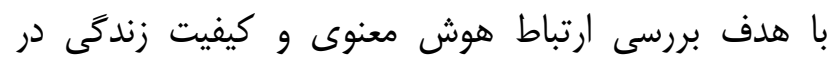
يرستاران اين شهر صورت گرفت. بروسي ارتباط هوت 


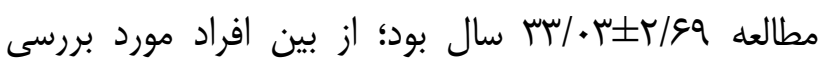

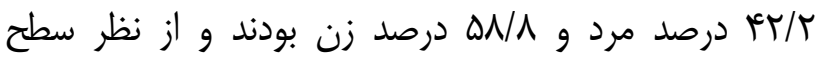

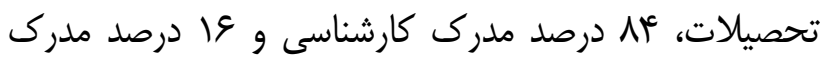
كارشناسى ارشد داشتند. جدول يك ميانخين و انحرافمعيار هر يك از حيطههاى هوش معنوى و نمره كل هوش معنوى را نشان مى مدهد.

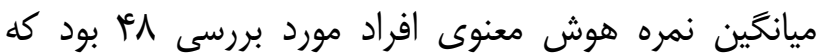

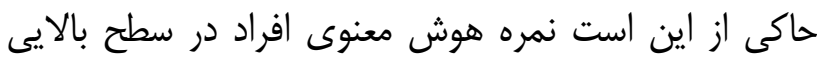

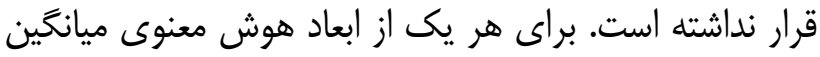

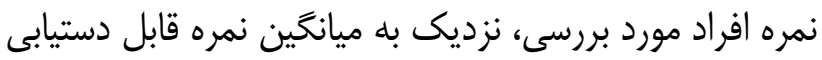

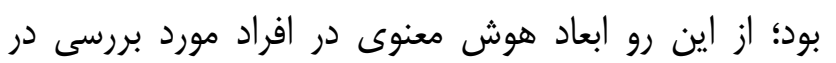
سطح متوسط قرار داشت.

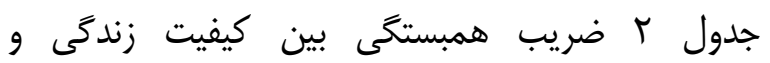

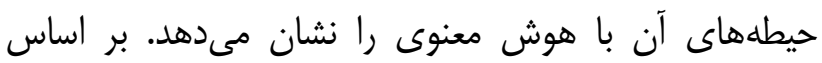

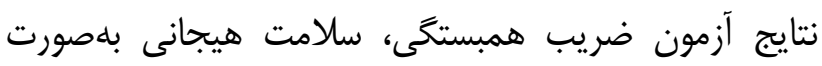

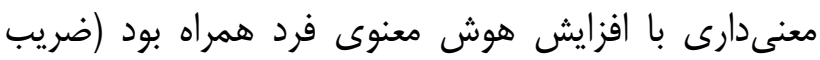

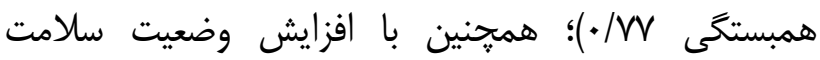
عمومى فرد، هوش هيجانى فرد افزايش مىيافت (ضريب التيب

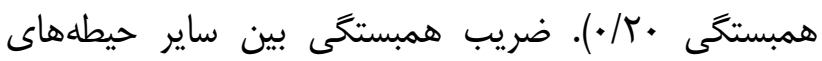
كيفيت زندگى و هوش معنوى معنى دار نبود.
نشاندهنده ميزان بالاى هوش معنوى افراد است (^). حسين

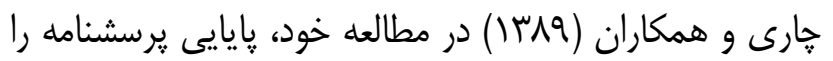

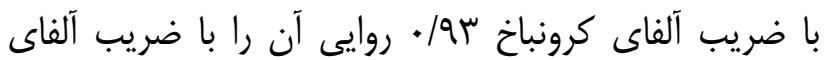

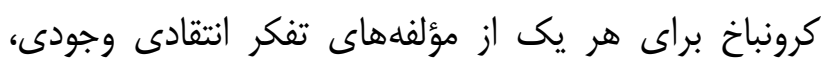

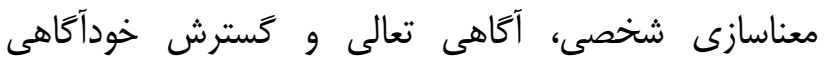

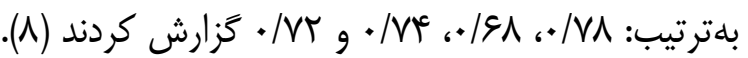
اين مقاله بركرفته از طرح تحقيقاتى مصوب دانشعاه علهاه علوم

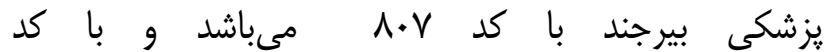
ir.bums.rec1394.463 اخلاق بئل در كميته اخلاق اين دانشگاه به ثبت رسيده است. لازم به ذكر است ورود افراد به اين مطالعه با رضايت و آكاهى بوده آداه است؛ همجنين :رسش نامهها بلدون نام و مشخصات بودهاند.در اين مطالعه يس إز ورود دادهها به نرمافزار SPSS

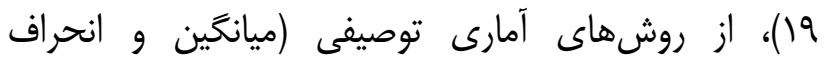
استاندارد) براى شرح و توصيف دادهها و از آمار استنباطى إنى (آزمون همبستخى) براى تجزيه و تحليل دادهها استفاده شد.

\section{يافتهها}

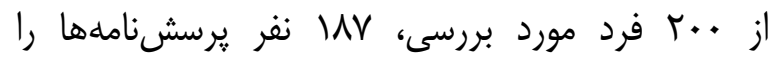
بلهورت كامل تكميل كردند. ميانگين سنى افراد مورد جدول ا- ميانكَين و انحر اف هوش معنوى و ابعاد آن در افراد مورد بررسى

\begin{tabular}{|c|c|c|}
\hline انحر افمعيار & ميانكَين & حيطه \\
\hline $11 / \pi r$ & IN/G. & نمره كل \\
\hline T/Rg & س & تفكر وجودى انتقادى \\
\hline$r / \cdot q$ & $1 . / 9$ & توليد معناى شخصى \\
\hline r/A & $|r / 9|$ & آَاهى متعالى \\
\hline$r / .9$ & $q / r V$ & بسط حالت هشيارى \\
\hline
\end{tabular}


جدول r- ضريب همبستكى بين نمره هوش معنوى با كيفيت زندكى و حيطه هاى آن

\begin{tabular}{|c|c|c|}
\hline سطح معنى دارى & ضريب همبستكى & متغيتر \\
\hline$\cdot / \Delta \Delta$ & $.1 \cdot 0$ & كار كرد جسمى \\
\hline K. &.$/ 11$ & اختلال نقش بخاطر سلامت جسمى \\
\hline$\cdot / \cdots 1$ & $\cdot / \mathrm{V}$ & ختلال نقش بخاطر سلامت هيجانى \\
\hline.$/ 19$ & $.1 \cdot 1$ & انرزى/خستخى \\
\hline Trt & $\cdot 1 \cdot 1$ & بهزيستى هيجانى \\
\hline$\cdot / 4 r$ & .1 .9 & كاركرد اجتماعى \\
\hline.$/ T \Lambda$ & .1 .9 & درد \\
\hline.$/ \cdot r$ &.$/ r$ & 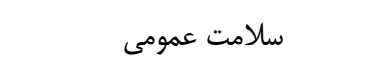 \\
\hline$\cdot|\Delta|$ & .1 .9 & زير مقياس سلامت جسمى \\
\hline.$/ 48$ & $\cdot 1 \cdot 1$ & زيرمقياس سلامت روانى \\
\hline
\end{tabular}

معنوى يرستاران، ضرورى به نظر مىرسد (9).

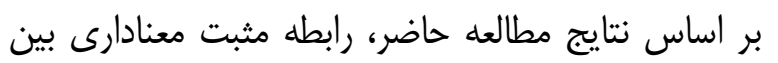

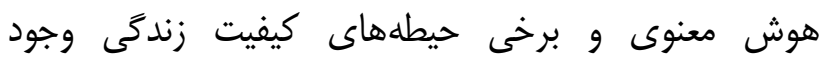
دارد.همسو با اين نتيجه از مطالعه حاضر، نتايج مطالعه

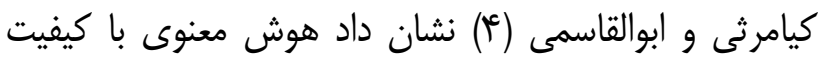

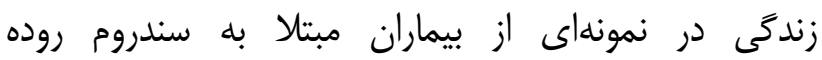

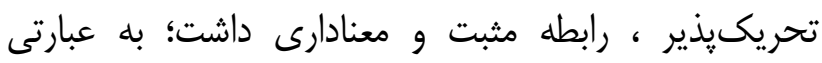
هوش معنوى مىتواند باعث بهبود كيفيت زندگى در افراد

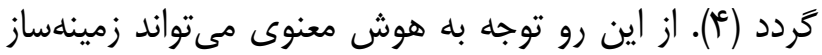
بهبود كيفيت زندگى افراد باشد. هوش معنوى باعث رشد توانايى افراد و درك احساسات

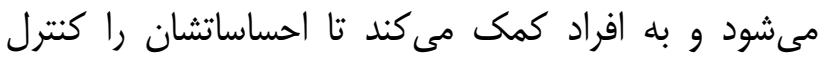

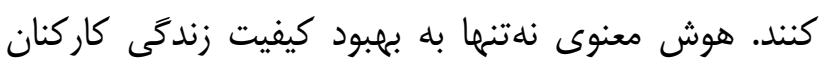

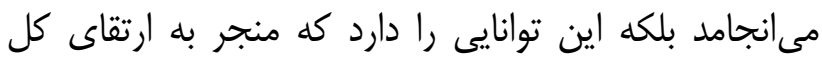

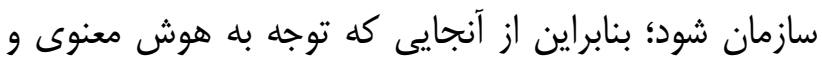

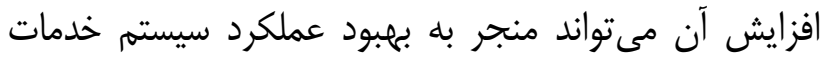

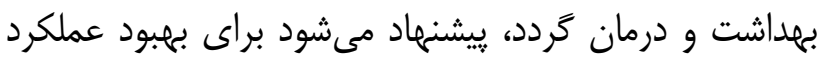

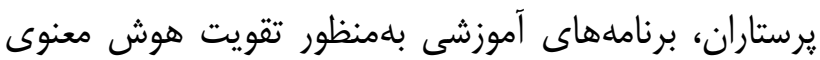

هدف از اين مطالعه، بررسى وضعيت هوش معنوى و

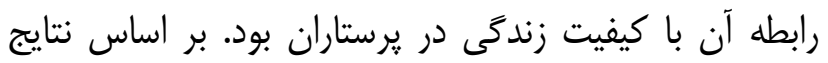
اين مطالعه، ميانگين نمره هوش معنوى يرستاران در سطح

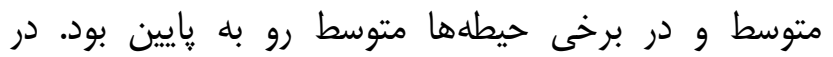

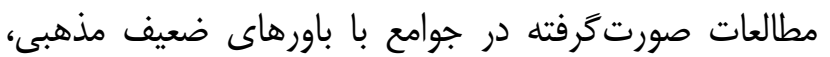

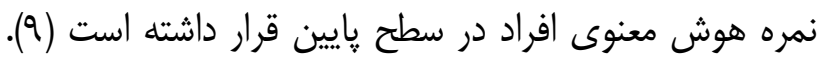

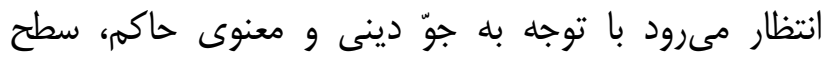
هوش معنوى افراد بالاتر باشد؛ از طرفى محيط شهر بير دجن كوخى است و به نظر مىرسد اعتقادات مذهبى در بين افراد

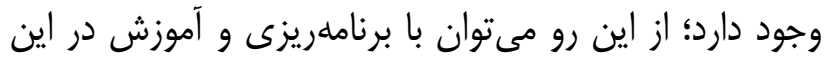

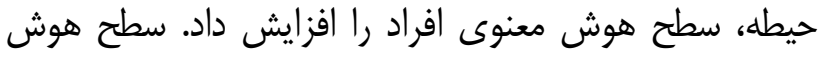

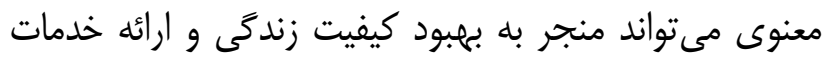

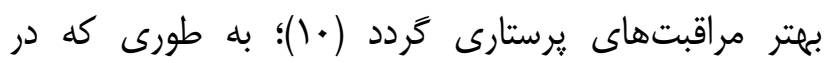

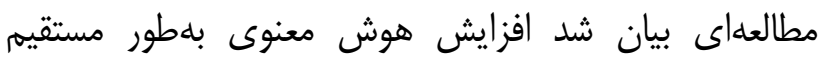

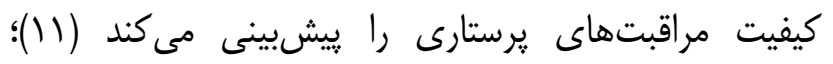

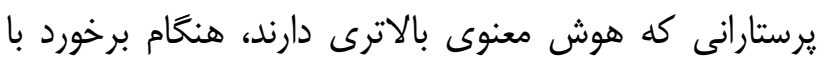

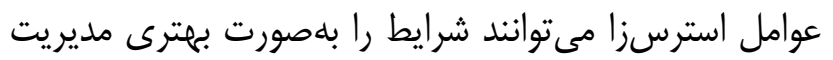

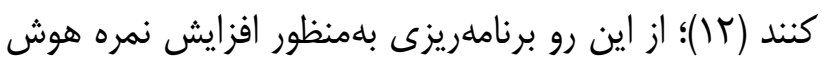




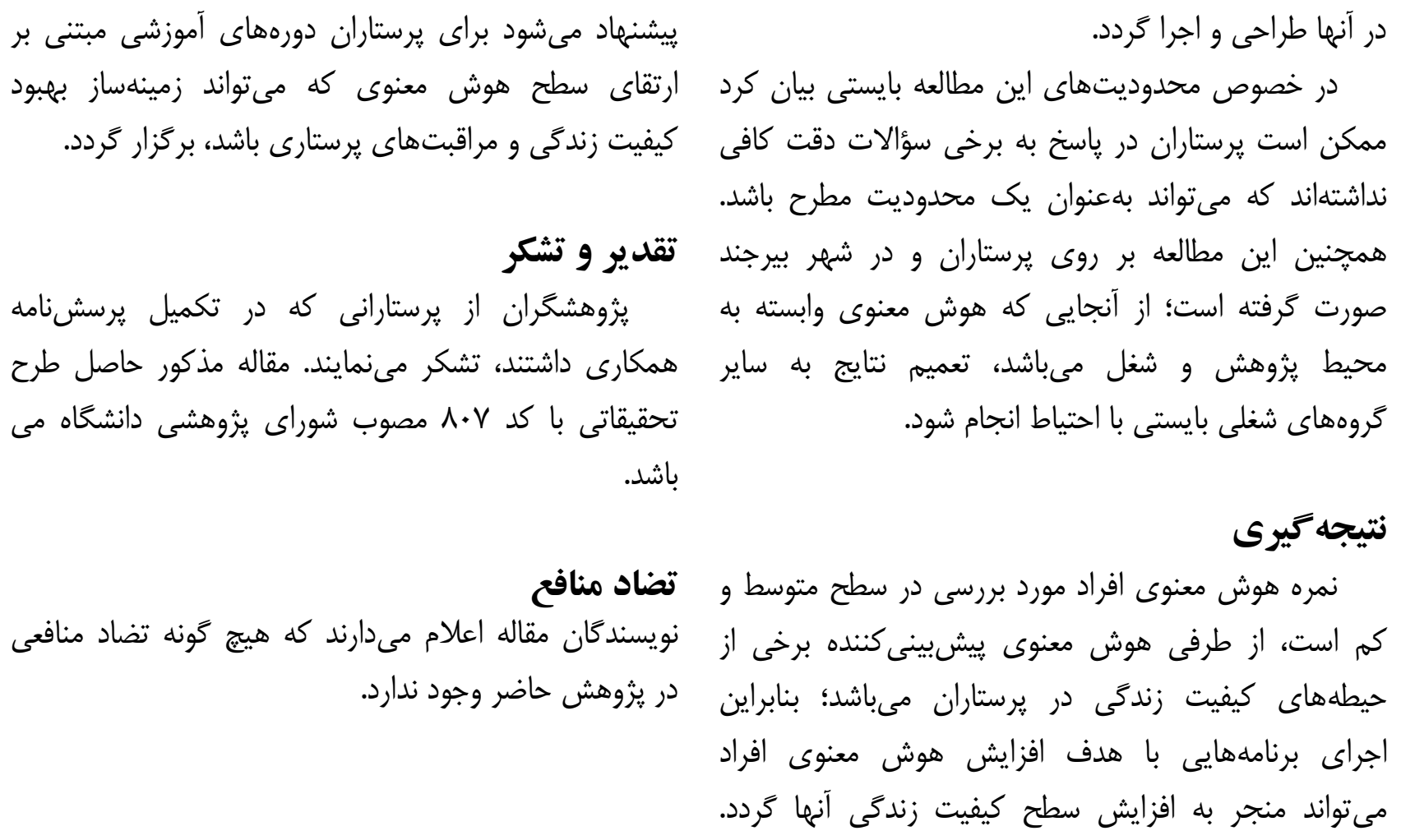

1- Emmons RA. Is spirituality an intelligence? Motivation, cognition, and the psychology of ultimate concern. Int $\mathrm{J}$ Psychol Relig. 2000; 10(1): 3-26. doi: 10.1207/S15327582IJPR1001_2

2- Varricchio CG, Ferrans CE. Quality of life assessments in clinical practice. Semin Oncol Nurs. 2010; 26(1): 12-7. doi: 10.1016/j.soncn.2009.11.003.

3- Yousefi F, Safari H. The effect of Emotional Intelligence on Quality of Life and its dimensions. Quarterly Journal of Psychological Studies. 2010; 5(4): 107-28. doi: 10.22051/psy.2009.1615. [Persian]

4- Kiamarsi A, Abolghasemi A. Emotional intelligence and frustration: predictors of quality of life in patients with irritable bowel syndrome. Procedia Soc Behav Sci. 2010; 5: 827-31. doi: 10.1016/j.sbspro.2010.07.193.

5- Mardani Hamule M, Shahraky Vahed A. The Assessment of Relationship between Mental Health and Quality of Life in Cancer Patients. Avicenna J Clin Med. 2009; 16(2): 33-8. [Persian]

6- Chiu MC, Wang MJJ, Lu CW, Pan SM, Kumashiro M, Ilmarinen J. Evaluating work ability and quality of life for clinical nurses in Taiwan. Nurs Outlook. 2007; 55(6): 318-26. doi: 10.1016/j.outlook.2007.07.002.

7- Montazeri A, Goshtasbi A, Vahdaninia MS. The short form health survey (SF-36): translation and validation study of the iranian version. Payesh. 2006; 5(1): 49-56. [Persian]

8- King D. Rethinking claims of spiritual intelligence: A definition, model, and measure: ProQuest; 2009.

9- Miri K, Keshavarz A, Shirdelzadeh S, Parsa M. The relationship between nurses' spiritual intelligence and quality of nursing care based on nurses' \& patients' viewpoints. J Urmia Nurs Midwifery J. 2015; 13(6): 518-24. [Persian]

10- Merkouris A, Papathanassoglou ED, Lemonidou C. Evaluation of patient satisfaction with nursing care: quantitative or qualitative approach? Int J Nurs Stud. 2004; 41(4): 355-67. doi: 10.1016/j.ijnurstu.2003.10.006. 
11- Bagheri F, Akbarizadeh F, Hatami H. The Relationship between Spiritual Intelligence and Happiness on the Nurse Staffs of the Fatemeh Zahra Hospital and Bentolhoda Institute of Boushehr City. Iran South Med J. 2011; 14(4): 256-63. [Persian]

12- Neishabory M, Raeisdana N, Ghorbani R, Sadeghi T. Nurses' and patients' viewpoints regarding quality of nursing care in the teaching hospitals of Semnan University of Medical Sciences, 2009. Koomesh. 2011; 12(2): 134-43. [Persian] 